pulse ultrasound: its reproducibility, validation and variability. Brf Dermatol 1982;106:657-67.

12 Edwards $\mathrm{C}$. The use of high frequency ultrasound for the study of structure and dimensions of skin. Manchester: University of Manchester Faculty of Technology, 1985. (PhD thesis.)

13 Boyle J, Briggs JI), Mackie RM, Junor BJR, Aitchison TC. Cancer, warts and sunshine in renal transplant patients. Lancet 1984;i:702-5.

14 Shuttleworth D, Marks R, Griffin PJA, Salaman JR. Dysplastic epidermal changes in immunosuppressed patients with renal transplants. Qf Med 1987;64:609-16

5 Miller RG. Simultuneous statistical inferences. 2nd ed. Berlin: Springer Verlag, 1981:165-7.

16 Gardner MJ, Altman DG. Statistics with confidence-confidence intervals and statistical guidelines. London: British Medical Journal, 1989:72.

17 Reid DM, Nicholl JJ, Smith MA, Higgins B, Tothill P, Nuki G. Corticosteroids and bone mass in asthma: comparisons with rheumatoid arthritis and polymyalgia rheumatica. Br Med f 1986;293:1463-6.

18 Crompton GK. Corticosteroids and bone mass in asthma. Br Med F 1987;294: 123.

19 Tan CY, Marks R, Payne P. Comparison of xeroradiographic and ultrasound detection of corticosteroid induced dermal thinning. I Invest Dermatol $1981 ; 76: 126-8$.

20 Dykes PJ, Marks R. An appraisal of the methods used in the assessment of atrophy from topical corticosteroids. Brf Dermatol 1979;101:599-609.

21 Rook A, Wilkinson DS, Ebling FJE, Champion RH, Burton JL, eds. Glucocorticosteroid induced atrophy. In: Textbook of dermatology. London: Blackwell Scientific, 1986:1814

22 Dykes PJ, Hills S, Marks R. Assessment of the atrophogenicity potential of corticosteroids by ultrasound and by epidermal biopsy under occlusive and non-occlusive conditions. In: Christopher AL, ed. Topical corticosteroid therapy: a new approach to safer drug therapy. New York: Raven Press, 1988:111-21

23 David MJ. Skin trauma in patients receiving systemic corticosteroid therapy. BrMed 7 1972;ii:614-6.

24 Gottlieb NL, Penneys NS. Spontaneous skin tearing during systemic corticosteroid treatment. FAMA 1980;243:1260-1.

25 McLeod DT, Capewell S, Law J, McLaren W, Seaton A. Intramuscular triamcinolone acetonide in chronic severe asthma. Thorax 1985;40:840-5.

26 Gaddie J, Reid IW, Skinner C, Petrie GR, Sinclair DJM, Palmer KNV. Aerosol beclomethasone dipropionate - a dose response study in chronic bronchial asthma. Lancet 1973;ii:280-1.

27 Kruszynska YT, Greenstone M, Home PD, Cooke NJ. Effect of high dose inhaled beclomethasone dipropionate on carbohydrate and lipid metabolism in normal subjects. Thorax 1987;42:881-5.

28 Ali NJ, Capewell S, Ward M. Bone turnover during high dose inhaled corticose

29 Littlewood JM, Johnson AW, Edwards PA, Littlewood AE. Growth retardation in asthmatic children treated with inhaled beclomethasone retardation in asthmatic children

30 Karim AKA, Thompson GM, Jacob TJC. Steroid aerosols and cataract formation. Br Med F 1989:299:918.

31 Brincat $M$, Yuen AWT, Studd JWW, et al. Response of skin thickness and metacarpal index to estradiol therapy in post-menopausal women. Obstet Gynecol 1987;70:538-41.

\title{
A randomised controlled trial of surgery for glue ear
}

\author{
N A Black, C F B Sanderson, A P Freeland, M P Vessey
}

\section{Abstract}

Objective-To assess the effect of five different surgical treatments for glue ear (secretory otitis media) on improvement in hearing and, assuming one or more treatments to be effective, to identify the appropriate indications for surgery.

Design-Randomised controlled trial of children receiving $(a)$ adenoidectomy, bilateral myringotomy, and insertion of a unilateral grommet; $(b)$ adenoidectomy, unilateral myringotomy, and insertion of a unilateral grommet; $(c)$ bilateral myringotomy and insertion of a unilateral grommet; and $(d)$ unilateral myringotomy and insertion of a grommet. Children were followed up at seven weeks, six months, 12 months, and 24 months by symptom history and clinical investigations.

Setting-Otolaryngology department in an urban hospital.

Patients-149 Children aged 4-9 years who were admitted for surgery for glue ear and who had no history of previous operations on tonsils, adenoids, or ears and no evidence of sensorineural deafness. Inadequate follow up information on levels of hearing and on middle ear function was obtained from 22.

Main outcome measures-Mean hearing loss (dB) of the three worst heard frequencies between 250 and $4000 \mathrm{~Hz}$, results of impedance tympanometry, and parental views on their child's progress.

Results - In the 127 children for whom adequate information was available ears in which a grommet had been inserted performed better in the short term (for at least six months) than those in which no grommet had been inserted, irrespective of any accompanying procedure. Most of the benefit had disappeared by 12 months. Adenoidectomy produced a slight improvement that was not significant, though was sustained for at least two years. The ears of children who had had an adenoidectomy with myringotomy and grommet insertion, however, continued to improve so that two years after surgery about $50 \%$ had abnormal tympanometry compared with $83 \%$ of those who had had only myringotomy and grommet insertion, and $\mathbf{9 3 \%}$ of the group that had had no treatment. Logistic regression analyses identified preoperative hearing level as the single best predictor of good outcome from surgery. Other variables contributed little additional predictive power.

Conclusions - If the principal objective of surgery for glue ear is to restore hearing then our study shows that insertion of grommets is the treatment of choice. The addition of an adenoidectomy will increase the likelihood of restoration of normal function of the middle ear but will not improve hearing. When deciding appropriate indications for surgery, a balance has to be made between performing unnecessary operations and failing to treat patients who might benefit from surgical intervention. Preoperative audiometry scores might be the best predictor in helping to make this decision.

\section{Introduction}

Glue ear, or otitis media with effusion, is the commonest reason for elective surgery in childhood. 'In England and Wales in 1986 about 73000 operations were carried out in NHS hospitals (based on hospital activity analyses for Oxford and for East Anglian regional health authorities) and a further 18000 are estimated to have been performed in independent hospitals (J P Nicholl, personal communication). Despite the popularity of these operations considerable uncertainty exists about their efficacy and the appropriate indications for their use. Although the results of 15 randomised controlled trials concerning a total of 1549 children have been published since 1967, few of the studies can easily be compared. ${ }^{2-16}$ Variations of case definition, exclusion criteria, case severity, outcome measures, duration of follow up, and method of analysis have all contributed to the difficulty in achieving consensus. A further complication is that a variety of operative procedures in different combinations have been studied: adenoidectomy, myringotomy, and grommet (tympanostomy tube) insertion (table I).

Despite the difficulties entailed in making detailed comparisons between the trials it is possible to identify some consistent findings. Firstly, myringotomy results in little or no benefit. ${ }^{14} 16$ Secondly, myringotomy plus grommet insertion is effective for up to 12 months, ${ }^{2314}$ though two studies found that this procedure was not
Correspondence to

Dr Black. 
Treatment

\begin{tabular}{|c|c|c|c|c|c|}
\hline \multirow[b]{2}{*}{ Treatment 2} & & & & & \\
\hline & No treatment & Myringotomy & Myringotomy and grommet & Adenoidectomy & Adenoidectomy and myringotomy \\
\hline Adenoidectomy and grommet & Maw and Herod ${ }^{2}$ & Gates $e t a l^{3}$ & $\begin{array}{l}\text { Roydhouse } \\
\text { Widemar et al } \\
\text { Gates et al }\end{array}$ & $\begin{array}{l}\text { Lildholdt }^{6} \\
\text { Maw and Herod }\end{array}$ & $\begin{array}{l}\text { Richards et al } \\
\text { Bonding et al } \\
\text { Gates et al }\end{array}$ \\
\hline Adenoidectomy and myringotomy & & $\begin{array}{l}\text { Fiellau-Nikolajsen et } a l^{\prime \prime} \\
\text { Gates et } a l^{\prime \prime}\end{array}$ & Gates et al & & \\
\hline Adenoidectomy & $\begin{array}{l}\text { Rynnel-Dagoo et al" } \\
\text { Bulman et al } \\
\text { Maw and Herod }\end{array}$ & & Maw and Herod: & & \\
\hline Myringotomy and grommet & $\begin{array}{l}\text { Brown et } \text { al }^{14} \\
\text { Maw and Herod } \\
\text { Mandel et } \text { al }^{14} \\
\text { Zielhuis } \text { et al }\end{array}$ & $\begin{array}{l}\text { Mandel } \text { et }_{\text {al }}{ }^{14} \\
\text { Gates } \text { el }^{3} l^{3}\end{array}$ & & & . \\
\hline Myringotomy & $\begin{array}{l}\text { Archard'ts } \\
\text { Mandel } \text { et } a l^{14}\end{array}$ & & & & \\
\hline
\end{tabular}

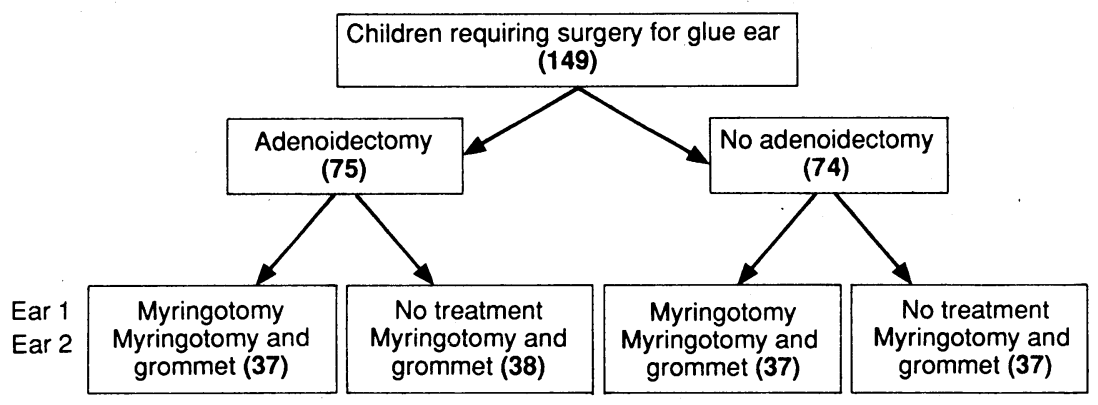

FIG 1-Treatment groups resulting from randomisation

effective. ${ }^{1315}$ Thirdly, adenoidectomy is effective, ${ }^{2312}$ though again two studies found that it had no effect. ${ }^{1011}$ Fourthly, grommet insertion and adenoidectomy are equally effective, ${ }^{23}$ though repeat surgery is needed more often after grommet insertion than after adenoidectomy. Finally, adenoidectomy combined with grommet insertion is no better than adenoidectomy alone $\mathrm{e}^{23689}$ or grommet insertion alone..$^{2.517}$

We had two objectives: to compare the relative effectiveness of the five different treatment strategies identified in table I and, assuming one or more treatment strategies to be effective, to identify the appropriate indications for surgery in the management of glue ear.

\section{Methods}

The parents of all children aged 4-9 years who were admitted to the Radcliffe Infirmary, Oxford, for surgery for bilateral glue ear between 1981 and 1986 were invited to allow their child to take part in the trial. Children who had previously had operations on their tonsils, their adenoids, or their ears and those in whom there was evidence of cleft palate or any sensorineural deafness were excluded. Children were also excluded if surgery for conditions other than glue ear was to be performed, such as adenoidectomy for alleviating gross nasal obstruction. The need for surgery was based on the clinical judgment of the otolaryngologist responsible for the care of each child, regardless of any findings on investigation.

Having obtained parental consent for inclusion in the trial, we randomly divided the children into one of four treatment groups: $(a)$ adenoidectomy and bilateral myringotomy plus insertion of a unilateral grommet (standard Shepherd tympanostomy tube); (b) adenoidectomy plus a unilateral myringotomy and insertion of a grommet; $(c)$ bilateral myringotomy plus insertion of a unilateral grommet; and $(d)$ a unilateral myringotomy and insertion of a grommet (fig 1). Randomisation between the right ear and the left ear for grommet insertion was also carried out. Instructions about the treatment allocated were contained in sealed numbered envelopes. The contents of the envelopes were determined with a table of random numbers. The clinicians who had obtained parental consent selected the next available envelope according to numerical sequence.

The minimum number of children that would be needed in the study to allow paired analysis and unpaired analysis to be performed was calculated based on the following assumptions. Firstly, we assumed that there would be a mean preoperative variation in hearing loss between a child's ears of 2 (SD 14.25) $\mathrm{dB},,^{13}$ and, secondly, that there would be a mean preoperative hearing loss of 32.5 (SD 11.4) $\mathrm{dB}^{18}$ Finally, we thought that $10 \mathrm{~dB}$ should be the minimum difference in levels of hearing between treatments that might be regarded as clinically important and that the trial should have a $95 \%$ chance of detecting such a difference between two treatments at the $5 \%$ level of significance. These assumptions implied that about 104 children would be needed for paired analysis - that is, studying the difference in levels of hearing between the two ears in each child - and that about 136 would be needed for unpaired analysis-that is, comparison between treatment groups. We envisaged that about $10 \%$ of the children would be lost to follow up before the end of the study, so 149 children were entered into the study.

Information about the child's age, sex, social class (based on the father's occupation, or the mother's when the child was living in a single parent family), and history of symptoms (deafness, otalgia, nasal obstruction, and speech development) was recorded on a preoperative form that was completed by a doctor. In addition, pure tone audiometry (from 250 to $4000 \mathrm{~Hz}$ ) and impedance tympanometry were carried out. When a myringotomy was performed a record was made of whether the middle ear was dry, contained serous fluid, or contained "glue."

Each child was followed up for two years and was reviewed at seven weeks, six months, 12 months, and 24 months. At each visit the following information was obtained: parental views on their child's progress, results of a pure tone audiogram, and results of a tympanogram. The children were not assessed by otoscopy because of the considerable interobserver variation associated with the observations. The audiometricians were blind to the treatment that the children had received. Children who did not attend their follow up appointment were sent another invitation. Attempts to get them to attend were abandoned only when they did not appear at three consecutive appointments.

Parental opinions on their child's treatment were defined as favourable, uncertain, or unfavourable. Parents were also asked to report any adverse side effects of treatment. In line with other trials audiometric performance was based on the mean hearing loss of the three worst heard frequencies. ${ }^{35616}$ Tympanometry results were classified according to both the shape of 
the recording and the pressure in the middle ear, and two categories were established: normal $(\mathrm{A}$ and $\mathrm{Cl})$ or abnormal (B and C2). ${ }^{19}$ Tympanometry was not performed on ears with grommets because valid recordings cannot be made when grommets are in place and are patent.

The organisers of the study recognised that after surgery the clinical management of each child remained the responsibility of the otolaryngologist concerned, and therefore any decision to carry out further or repeat surgery was beyond their control. The otolaryngologists were, however, asked to avoid further surgical treatment when possible. Data on repeat surgery were collected and analysed, but the children concerned were no longer followed up.

The statistical analyses consisted of: ( $a$ ) a comparison of the findings before operation and after operation in the four treatment groups using contingency tables; (b) the proportions of children in each group who had to have repeat surgery, and the findings at reoperation; (c) paired analysis of the audiometric findings for the left ear and the right ear in the same child using $t$ tests on the mean changes in hearing level since surgery; (d) independent comparisons of audiometric findings for the ears of different children after different surgical interventions using $t$ tests on the mean changes in hearing level since surgery; $(e)$ comparison of the proportions of children who had abnormal results on tympanometry and unfavourable parental opinion at follow up; $(f)$ multivariate analysis to link the outcome of grommet insertion to a set of preoperative variables using a range of outcome criteria.

\section{Results}

COMPARABILITY OF TREATMENT GROUPS

The children in the four treatment groups were comparable with regard to the stratification criteria of age, social class, and history of glue ear (table II) and findings on investigation (table III). The sex ratios differed, but there is no evidence to suggest that this would cause problems with confounding.

\section{FOLLOW UP}

Overall $48(32 \%)$ children underwent further surgery for glue ear during the two year follow up period, the proportion varying with the initial treatment group. Children who had undergone an adenoidectomy were less likely to have further surgery $(19 \% v 45 \%, \mathrm{p}<0.01)$, but this was not surprising as it is usually possible to undergo an adenoidectomy only once. A further $10(7 \%)$ children either did not attend follow up appointments or moved from the area. Most of the loss to follow up occurred more than 12 months after the initial operation: $85 \%$ were seen at 12 months but only $61 \%$ at 24 months.

\section{OUTCOMES}

Audiometry (paired analysis)-Audiometric data were not obtained on every occasion in 22 children

TABLE II - Preoperative characteristics of the children according to treatment group. Values are numbers (percentages)

\begin{tabular}{|c|c|c|c|c|}
\hline \multirow[b]{2}{*}{ Characteristic } & \multicolumn{4}{|c|}{ Treatment group } \\
\hline & $\begin{array}{c}\text { Adenoidectomy and } \\
\text { bilateral myringotomy } \\
\text { plus unilateral grommet (1) } \\
(\mathrm{n}=37)\end{array}$ & $\begin{array}{l}\text { Adenoidectomy plus } \\
\text { unilateral myringotomy } \\
\text { and grommet (2) } \\
\qquad(\mathrm{n}=38)\end{array}$ & $\begin{array}{l}\text { Bilateral myringotomy } \\
\text { plus unilateral } \\
\text { grommet }(3) \\
(\mathrm{n}=37)\end{array}$ & $\begin{array}{l}\text { Unilateral } \\
\text { myringotomy and } \\
\text { grommet }(4) \\
(n=37)\end{array}$ \\
\hline \multicolumn{5}{|l|}{ Social class: } \\
\hline Non-manual & $13(35)$ & $16(42)$ & $12(32)$ & $13(36)$ \\
\hline Manual & $18(49)$ & $18(47)$ & $20(55)$ & $21(56)$ \\
\hline \multirow{2}{*}{\multicolumn{5}{|c|}{ Pattern of deafness: }} \\
\hline & & & & \\
\hline Never & $1(3)$ & 0 & $2(5)$ & $2(5)$ \\
\hline Fluctuating & $23(62)$ & $21(55)$ & $24(66)$ & $18(49)$ \\
\hline Constant & $13(35)$ & $17(45)$ & $11(29)$ & $17(46)$ \\
\hline \multicolumn{5}{|c|}{ Duration of deafness (months): } \\
\hline$\leqslant 9$ & $4(11)$ & $7(19)$ & $6(16)$ & $11(30)$ \\
\hline $10-18$ & $14(37)$ & $13(34)$ & $13(35)$ & $9(24)$ \\
\hline$>18$ & $19(51)$ & $18(47)$ & $18(49)$ & $17(46)$ \\
\hline \multicolumn{5}{|c|}{ No of episodes of otalgia: } \\
\hline None & $11(30)$ & $15(40)$ & $12(32)$ & $12(33)$ \\
\hline $1-3$ & $20(54)$ & $12(32)$ & $16(42)$ & $14(39)$ \\
\hline$\geqslant 4$ & $6(16)$ & $11(29)$ & $9(26)$ & $11(28)$ \\
\hline \multicolumn{5}{|c|}{ Duration of otalgia (months): } \\
\hline$<6$ & $5(14)$ & $2(5)$ & $4(11)$ & $5(14)$ \\
\hline $6-12$ & $8(21)$ & $6(17)$ & $9(23)$ & $11(30)$ \\
\hline$>12$ & $24(64)$ & $30(79)$ & $24(65)$ & $21(57)$ \\
\hline \multicolumn{5}{|l|}{ Nasal symptoms: } \\
\hline None or mild & $11(30)$ & $13(35)$ & $18(48)$ & $16(44)$ \\
\hline Moderate or șevere & $26(70)$ & $25(65)$ & $19(52)$ & $21(56)$ \\
\hline \multicolumn{5}{|l|}{ Speech development: } \\
\hline Normal & $30(81)$ & $33(87)$ & $29(79)$ & $33(90)$ \\
\hline Abnormal & $7(19)$ & $5(13)$ & $8(21)$ & $4(10)$ \\
\hline Mean (SE) age (years) & $6 \cdot 3(0 \cdot 23)$ & $6 \cdot 6(0.23)$ & $6 \cdot 1(0 \cdot 21)$ & $6 \cdot 0(0.21)$ \\
\hline Sex (male:female) & 1.06 & $1 \cdot 11$ & 1.92 & 1.79 \\
\hline
\end{tabular}

TABLE III-Preoperative investigations and operative findings according to treatment group. Hearing level is the mean of the three worst heard frequencies

\begin{tabular}{|c|c|c|c|c|}
\hline \multirow[b]{2}{*}{ Investigation or finding } & \multicolumn{4}{|c|}{ Treatment group } \\
\hline & $\begin{array}{c}\text { Adenoidectomy and } \\
\text { bilateral myringotomy } \\
\text { plus unilateral grommet (1) } \\
(\mathrm{n}=37)\end{array}$ & $\begin{array}{c}\text { Adenoidectomy plus } \\
\text { unilateral myringotomy } \\
\text { and grommet }(2) \\
(\mathbf{n}=38)\end{array}$ & $\begin{array}{l}\text { Bilateral myringotomy } \\
\text { plus unilateral } \\
\text { grommet }(3) \\
(\mathbf{n}=37)\end{array}$ & $\begin{array}{l}\text { Unilateral } \\
\text { myringotomy and } \\
\text { grommet }(4) \\
(n=37)\end{array}$ \\
\hline \multicolumn{5}{|l|}{ Hearing level $(\mathrm{dB})$ : } \\
\hline Left ear & $28 \cdot 1$ & $26 \cdot 9$ & $27 \cdot 6$ & $27 \cdot 8$ \\
\hline Right ear. & $29 \cdot 6$ & $29 \cdot 1$ & $29 \cdot 2$ & $27 \cdot 2$ \\
\hline \multicolumn{5}{|c|}{ Impedance (No (\%) abnormal): } \\
\hline Left ear & $35(95)$ & $30(79)$ & $31(84)$ & $27(73)$ \\
\hline Right ear & $35(95)$ & $36(95)$ & $29(78)$ & $29(78)$ \\
\hline \multicolumn{5}{|c|}{ Middle ear contents (No(\%)): } \\
\hline Dry & $11(30)$ & $15(39)$ & $9(24)$ & $16(44)$ \\
\hline Serous & $7(19)$ & $3(8)$ & $4(10)$ & $2(5)$ \\
\hline Glue & $19(51)$ & $20(53)$ & $24(66)$ & $19(51)$ \\
\hline
\end{tabular}


and therefore these children were omitted from the analysis. The effect of grommet insertion was assessed in each child by comparing the change in the hearing level (mean of the levels of the three worst heard frequencies) between the ears with and without a grommet. The data were initially analysed without taking into account any loss to follow up. The results are shown in table IV (raw data). Overall, ears in which a grommet had been inserted performed better in the short term (up to 12 months after surgery) than those in which no grommet had been inserted, irrespective of any accompanying procedures. Losses to follow up occurred for two reasons: repeat surgery and non-attendance at the outpatient clinic. The mean level of hearing of those needing further surgery had deteriorated by about $2 \mathrm{~dB}$ during the 12 months since their initial operation compared with an improvement of about $8 \mathrm{~dB}$ in those not requiring further intervention. It was possible that those children who had not attended their outpatient appointments had experienced a favourable outcome from surgery. To allow for these potential biases at the 12 and 24 month reviews we modified the raw data by assuming that without repeat surgery the levels of hearing would not have altered from the last recorded level. To test this assumption the analysis was repeated twice, allowing first for a deterioration of $10 \%$ in the hearing levels since the last recorded level and then for an improvement of $10 \%$. These variant assumptions made little difference to the results.

Audiometry (independent comparisons) - Independent (rather than within child) comparisons of changes in mean audiometry scores for the different surgical interventions are shown in table V. It was apparent that myringotomy had no discernible effect compared with no treatment. In contrast, levels of hearing improved with both myringotomy plus grommet insertion and adenoidectomy. The outcome after the combined operation (adenoidectomy plus myringotomy and grommet insertion) confirmed these findings. There was little difference initially between the outcome of the combined operation and that obtained with myringotomy and grommet insertion alone (fig 2). Sensitivity analysis with different modifications to the raw data (again allowing for a deterioration of $10 \%$ in the levels of hearing since the last recorded level and an improvement of $10 \%$ ) made little impact on the results, and comparisons of absolute values of the levels of

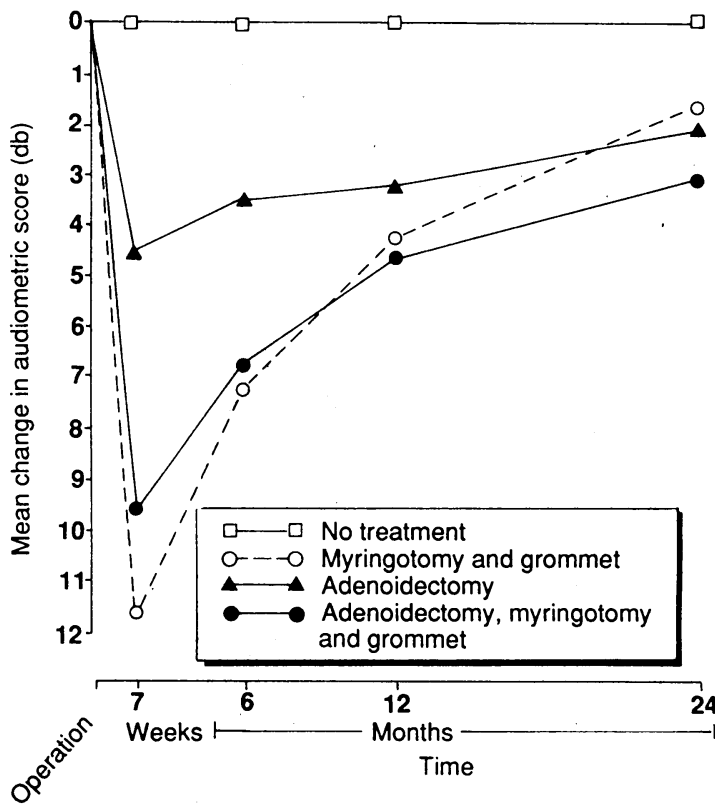

FIG 2-Independent comparisons of changes in mean audiometry scores for several different treatments using modified data

hearing on follow up, rather than changes from the preoperative levels, produced similar findings.

Tympanometry - In addition to the difficulties caused by the fairly high drop out rate during the second year of follow up the results of tympanometry were also affected by the lack of data during the first year of follow up for those ears in which a grommet had been inserted (because tympanometry could not be performed as a satisfactory seal cannot be achieved after grommet insertion). Because myringotomy had no effect on the levels of hearing the findings on tympanometry were analysed according to four groups (fig 3). Because of the preoperative differences in the proportions of abnormal readings changes in proportions were used in the analysis. During the second year the ears of children who had had an adenoidectomy continued to improve so that two years after surgery about half of them had abnormal tympanograms compared with $83 \%$ of those who had had a myringotomy plus grommet insertion, and $93 \%$ of those who had had either a myringotomy or no treatment.

TABLE IV - Within child comparison of change in mean results of audiometry (dB) with time after surgery according to treatment group: raw and modified data. Values are numbers (95\% confidence intervals)

\begin{tabular}{|c|c|c|c|c|c|c|}
\hline \multirow[b]{2}{*}{ Treatment group comparisons } & \multicolumn{4}{|c|}{ Time after operation (raw data) } & \multicolumn{2}{|c|}{ Time after operation (modified data) } \\
\hline & 7 Weeks & 6 Months & 12 Months & 24 Months & 12 Months & 24 Months \\
\hline $\begin{array}{l}\text { Adenoidectomy, myringotomy and grommet } v \\
\text { adenoidectomy and myringotomy } \\
\text { Adenoidectomy } v \text { adenoidectomy, myringotomy and }\end{array}$ & $8 \cdot 1^{\star}(3 \cdot 0$ to $13 \cdot 3)$ & $2 \cdot 8(-1.9$ to $7 \cdot 4)$ & $-1 \cdot 0(-6 \cdot 1$ to $4 \cdot 0)$ & $0.7(-4.9$ to 6.4$)$ & $-0.9(-5.5$ to $3 \cdot 8)$ & $0.2(-4.9$ to $5 \cdot 3)$ \\
\hline $\begin{array}{l}\text { grommet } \\
\text { Myringotomy and grommet } v \text { myringotomy } \\
\text { Myringotomy and grommet } v \text { no treatment }\end{array}$ & $\begin{array}{r}3 \cdot 3(-0 \cdot 5 \text { to } 7 \cdot 1) \\
12 \cdot 7^{\star}(7 \cdot 9 \text { to } 17 \cdot 5) \\
3 \cdot 4(-0 \cdot 9 \text { to } 7 \cdot 6)\end{array}$ & $\begin{array}{l}2 \cdot 8(-2 \cdot 2 \text { to } 7 \cdot 8) \\
7 \cdot 4^{\star}(1 \cdot 4 \text { to } 13 \cdot 4) \\
3 \cdot 5^{\star}(0 \cdot 1 \text { to } 6 \cdot 9)\end{array}$ & $\begin{array}{l}1.9(-3 \cdot 6 \text { to } 7 \cdot 4) \\
3 \cdot 7(-0 \cdot 4 \text { to } 7 \cdot 8) \\
1 \cdot 0(-2 \cdot 1 \text { to } 4 \cdot 2)\end{array}$ & $\begin{array}{c}2 \cdot 2(-6 \cdot 0 \text { to } 10 \cdot 3) \\
0 \cdot 9(-2 \cdot 7 \text { to } 4 \cdot 6) \\
-2 \cdot 4(-8 \cdot 7 \text { to } 3 \cdot 9)\end{array}$ & $\begin{array}{l}2 \cdot 3(-2 \cdot 8 \text { to } 7 \cdot 4) \\
5 \cdot 5^{\star}(0 \cdot 9 \text { to } 10 \cdot 1) \\
2 \cdot 0(-1 \cdot 0 \text { to } 5 \cdot 1)\end{array}$ & $\begin{array}{l}2 \cdot 1(-3 \cdot 8 \text { to } 8 \cdot 1) \\
3 \cdot 4(-1 \cdot 1 \text { to } 8 \cdot 0) \\
0 \cdot 5(-3 \cdot 7 \text { to } 4 \cdot 6)\end{array}$ \\
\hline
\end{tabular}

^Significant $t$ value $(\mathrm{p}<0 \cdot 05)$.

TABLE $\mathrm{v}-$ Independent comparisons of changes in mean audiometry scores (dB) with time after surgery: raw and modified data. Values are numbers (95\% confidence intervals)

\begin{tabular}{|c|c|c|c|c|c|c|}
\hline \multirow[b]{2}{*}{ Treatment group comparisons } & \multicolumn{4}{|c|}{ Time after operation (raw data) } & \multicolumn{2}{|c|}{ Time after operation (modified data) } \\
\hline & 7 Weeks & 6 Months & 12 Months & 24 Months & 12 Months & 24 Months \\
\hline Myringotomy $v$ no surgery & $1 \cdot 0(-4 \cdot 7$ to $6 \cdot 6)$ & $-0.6(-7 \cdot 0$ to $5 \cdot 9)$ & $-1 \cdot 1(-8 \cdot 1$ to $5 \cdot 8)$ & $-2 \cdot 3(-9 \cdot 1$ to $4 \cdot 5)$ & $1 \cdot 2(-5 \cdot 3$ to $7 \cdot 8)$ & $0.7(-5.5$ to $7 \cdot 0)$ \\
\hline Myringotomy and grommet $v$ no surgery & $11.7 \star(5.8$ to $17 \cdot 6)$ & $8.0 *(1.5$ to 14.5$)$ & $4 \cdot 8(-2 \cdot 4$ to $11 \cdot 9)$ & $3 \cdot 2(-4 \cdot 1$ to $10 \cdot 5)$ & $4 \cdot 3(-2 \cdot 2$ to $10 \cdot 8)$ & $2 \cdot 7(-3.2$ to $8 \cdot 6)$ \\
\hline Adenoidectomy $v$ no surgery & $4 \cdot 5(-1 \cdot 3$ to $10 \cdot 4)$ & $4 \cdot 3(-1 \cdot 4$ to $9 \cdot 9)$ & $4 \cdot 3(-3 \cdot 1$ to $11 \cdot 6)$ & $2 \cdot 4(-5.7$ to $10 \cdot 5)$ & $3 \cdot 2(-3.5$ to $10 \cdot 0)$ & $3 \cdot 5(-3 \cdot 2$ to $10 \cdot 3)$ \\
\hline Myringotomy and grommet $v$ adenoidectomy & $3 \cdot 0(-2 \cdot 1$ to $8 \cdot 1)$ & $1 \cdot 2(-4 \cdot 1$ to $6 \cdot 6)$ & $-1.4(-7.5$ to 4.8$)$ & $-3 \cdot 5(-11 \cdot 4$ to $4 \cdot 6)$ & $-0 \cdot 2(-5 \cdot 9$ to $5 \cdot 5)$ & $-2 \cdot 7(-8 \cdot 7$ to $3 \cdot 3)$ \\
\hline Adenoidectomy, myringotomy and grommet $v$ no surgery & $9 \cdot 6^{\star}(4 \cdot 3$ to $14 \cdot 8)$ & $7 \cdot 6^{\star}(2 \cdot 1$ to $13 \cdot 0)$ & $5 \cdot 3(-1 \cdot 3$ to 11.9$)$ & $5.9(-1.9$ to $13 \cdot 3)$ & $4 \cdot 6(-1 \cdot 3$ to $10 \cdot 4)$ & $5 \cdot 9(-0.2$ to $12 \cdot 0)$ \\
\hline $\begin{array}{l}\text { Adenoidectomy, myringotomy and grommet } v \\
\text { adenoidectomy } \\
\text { Adenoidectomy, myringotomy and grommet } v \text { myringotomy }\end{array}$ & $6.9 \star(0.8$ to 13.0$)$ & $3 \cdot 8(-2 \cdot 6$ to $10 \cdot 2)$ & $0 \cdot 0(-4 \cdot 0$ to $4 \cdot 0)$ & $4 \cdot 3(-4 \cdot 4$ to $13 \cdot 0)$ & $0 \cdot 3(-6 \cdot 8$ to $7 \cdot 4)$ & $2 \cdot 6(-4 \cdot 7$ to $9 \cdot 8)$ \\
\hline and grommet & $2 \cdot 0(-2 \cdot 3$ to $6 \cdot 4)$ & $2 \cdot 1 \cdot(-2 \cdot 6$ to $6 \cdot 8)$ & $2 \cdot 4(-2 \cdot 7$ to $7 \cdot 6)$ & $6 \cdot 9 \star(0 \cdot 3$ to $13 \cdot 7)$ & $1 \cdot 5(-3 \cdot 3$ to $6 \cdot 4)$ & $5 \cdot 1(0 \cdot 0$ to $10 \cdot 2)$ \\
\hline
\end{tabular}

${ }^{\star}$ Significant $t$ value $(\mathrm{p}<0 \cdot 05)$. 
TABLE VI-Comparisons of power of different preoperative levels of hearing to predict relative improvement in mean audiometric score of at least $5 \mathrm{~dB}$ and at least $10 \mathrm{~dB}$ six and 12 months after surgery. Predictor refers to mean preoperative level of hearing taken to indicate operation

\begin{tabular}{|c|c|c|c|c|c|}
\hline \multirow[b]{2}{*}{$\begin{array}{l}\text { Predictor } \\
\text { (dB) }\end{array}$} & \multicolumn{2}{|r|}{ Operation indicated } & \multicolumn{2}{|r|}{ Operation not indicated } & \multirow{2}{*}{$\begin{array}{c}\% \text { Of whole group } \\
\text { denied benefit } \\
\text { from surgery } \\
\text { (95\% confidence interval) }\end{array}$} \\
\hline & No & $\begin{array}{l}\% \text { With good outcome } \\
\text { ( } 95 \% \text { confidence interval) }\end{array}$ & No & $\begin{array}{l}\% \text { With good outcome } \\
(95 \% \text { confidence interval })\end{array}$ & \\
\hline
\end{tabular}

\begin{tabular}{|c|c|c|c|c|c|}
\hline \multicolumn{6}{|c|}{ Improvement $\geqslant 10 \mathrm{~dB}$ six months postoperatively } \\
\hline $\begin{array}{l}30 \\
25 \\
20 \\
15\end{array}$ & $\begin{array}{r}53 \\
79 \\
96 \\
117\end{array}$ & $\begin{array}{l}45(32 \text { to } 59) \\
38(27 \text { to } 50) \\
33(25 \text { to } 44) \\
28(20 \text { to } 37)\end{array}$ & $\begin{array}{l}74 \\
48 \\
31 \\
10\end{array}$ & $\begin{array}{r}14 \quad(7 \text { to } 24) \\
8 \quad(3 \text { to } 21) \\
6 \quad(1 \text { to } 23) \\
10 \quad(0 \text { to } 46)\end{array}$ & $\begin{array}{ll}8 & (4 \text { to } 14) \\
3 & (1 \text { to } 8) \\
2 & (0 \text { to } 6) \\
1 & (0 \text { to } 5)\end{array}$ \\
\hline \multicolumn{6}{|c|}{ Improvement $\geqslant 10 \mathrm{~dB} 12$ months postoperatively } \\
\hline $\begin{array}{l}30 \\
25 \\
20 \\
15\end{array}$ & $\begin{array}{r}53 \\
80 \\
100 \\
121\end{array}$ & $\begin{array}{l}36(23 \text { to } 50) \\
29(19 \text { to } 40) \\
25(17 \text { to } 35) \\
22(15 \text { to } 31)\end{array}$ & $\begin{array}{r}76 \\
49 \\
29 \\
8\end{array}$ & $\begin{array}{r}11 \quad(5 \text { to } 20) \\
8 \quad(3 \text { to } 20) \\
7 \quad(1 \text { to } 24) \\
0 \quad(0 \text { to } 40)\end{array}$ & $\begin{array}{ll}6 & (3 \text { to } 12) \\
3 & (1 \text { to } 8) \\
2 & (0 \text { to } 6) \\
0 & (0 \text { to } 4)\end{array}$ \\
\hline \multicolumn{6}{|c|}{ Improvement $\geqslant 5 d B$ six months postoperatively } \\
\hline $\begin{array}{l}30 \\
25 \\
20 \\
15\end{array}$ & $\begin{array}{r}53 \\
79 \\
96 \\
117\end{array}$ & $\begin{array}{l}57(42 \text { to } 70) \\
53(42 \text { to } 64) \\
50(40 \text { to } 60) \\
44(35 \text { to } 54)\end{array}$ & $\begin{array}{l}74 \\
48 \\
31 \\
10\end{array}$ & $\begin{array}{l}34(23 \text { to } 46) \\
27(16 \text { to } 42) \\
23(10 \text { to } 42) \\
30(8 \text { to } 65)\end{array}$ & $\begin{array}{r}20(13 \text { to } 28) \\
10(6 \text { to } 17) \\
6(2 \text { to } 11) \\
2(0 \text { to } 7)\end{array}$ \\
\hline \multicolumn{6}{|c|}{ Improvement $\geqslant 5 \mathrm{~dB} 12$ months postoperatively } \\
\hline $\begin{array}{l}30 \\
25 \\
20 \\
15\end{array}$ & $\begin{array}{r}53 \\
80 \\
100 \\
121\end{array}$ & $\begin{array}{l}51(37 \text { to } 65) \\
46(35 \text { to } 58) \\
40(30 \text { to } 50) \\
36(28 \text { to } 46)\end{array}$ & $\begin{array}{r}76 \\
49 \\
29 \\
8\end{array}$ & $\begin{array}{l}28(18 \text { to } 39) \\
22(12 \text { to } 37) \\
28(13 \text { to } 47) \\
50(17 \text { to } 82)\end{array}$ & $\begin{aligned} 17 & (11 \text { to } 24) \\
9 & (5 \text { to } 15) \\
6 & (3 \text { to } 12) \\
3 & (1 \text { to } 8)\end{aligned}$ \\
\hline
\end{tabular}

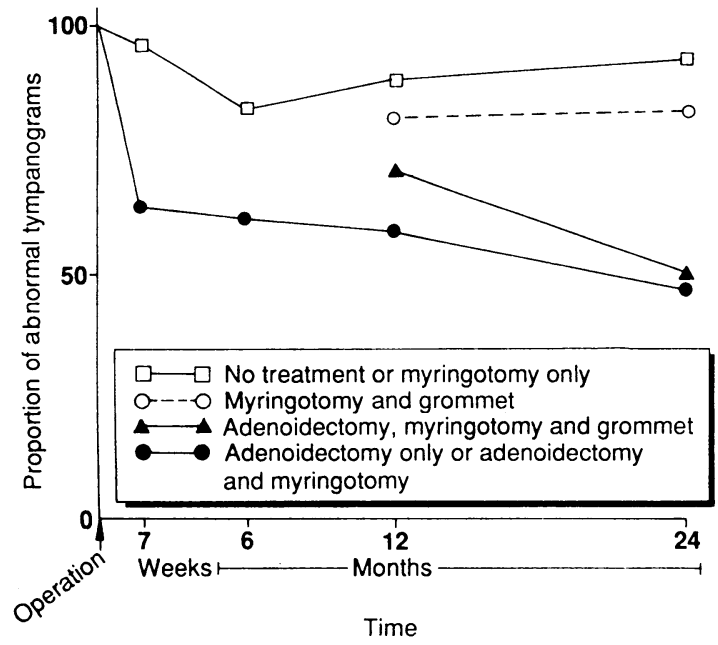

FIG 3-Proportion of ears with abnormal impedance ( $B$ and $C 2$ ) preoperatively that remained abnormal postoperatively for different treatment groups using modified data. No data were available for ears in which a grommet was in place

Parental opinion-It is difficult to assess the state of each of their child's ears separately. Parental opinion could therefore be used as an outcome measure only in relation to the four treatment groups. The parents of children who had had an adenoidectomy were more satisfied than those whose children had not (fig 4). This difference persisted throughout the two years of follow up so that by the end of the second year about half of the children who had not had an adenoidectomy were thought to be satisfactory compared with around $60-70 \%$ of those who had.

\section{INDICATIONS FOR SURGERY}

Logistic regression analyses were carried out to establish the appropriate indications for inserting grommets with or without adenoidectomy. The predictive power of a wide range of variables was considered: patient characteristics (age, sex, social class); symptoms (deafness, otalgia, nasal obstruction, speech); findings on investigation (hearing level, impedance); and findings at operation (middle ear contents). With the outcome criterion being defined as a relative improvement in hearing level of $10 \mathrm{~dB}$ after 12 months in the ear that had a grommet compared with the ear that did not, the data were examined for a subset of variables that had some predictive power. The most useful were the preoperative hearing level and the contents of the middle ear. Other variables contributed little additional predictive power. As the purpose of this analysis was to provide a basis for decisions about whether to operate, further analyses omitted the contents of the middle ear as this information may be reliably obtained only during surgery.

The accuracy of using preoperative audiometry scores as the sole predictor of outcome was tested using various different mean (for left and right ears together) preoperative hearing levels as indicative of surgery and two levels of improvement $(5 \mathrm{~dB}$ and $10 \mathrm{~dB})$, at six and 12 months after the operation, as indicative of a satisfactory outcome (table VI). At six months the proportion of children who had an improvement of $10 \mathrm{~dB}$ or more was $38 \%$ among those whose preoperative hearing loss was $25 \mathrm{~dB}$ or more $(95 \%$ confidence interval $27 \%$ to $50 \%$ ). At 12 months this had dropped to $29 \%$ ( $95 \%$ confidence interval $19 \%$ to $40 \%$ ). The corresponding figures among those whose preoperative hearing loss was less than $25 \mathrm{~dB}$ was $8 \%$ at both six months and 12 months $(95 \%$ confidence interval $3 \%$ to $20 \%$ ).

\section{Discussion}

This trial was designed to assess the effectiveness of surgery for glue ear rather than its efficacy. As such, no attempt was made to alter existing clinical practicefor example, by insisting that highly experienced senior surgeons assessed the children and performed the operations. Most of the surgery was performed by senior house officers and, with a steady turnover of medical staff, around 15 doctors of different grades were involved in the preoperative and postoperative care and assessment of patients. Recruitment of children took considerably longer than expected. This was due to failure by junior medical staff to attempt to recruit patients rather than a poor response rate. A comparison of the characteristics of the children included in the trial with those of the population of children undergoing surgery ${ }^{20}$ suggested that those included were representative and that no selection bias had operated. We believe that the clinical management the children experienced was fairly typical of otolaryngological practice in England and Wales in the 1980s. The results obtained are therefore likely to reflect the effectiveness of current practice.

The only important methodological problem experienced was the higher than predicted number of children whom we were unable to follow up for two years. The principal reason for this was the clinicians'

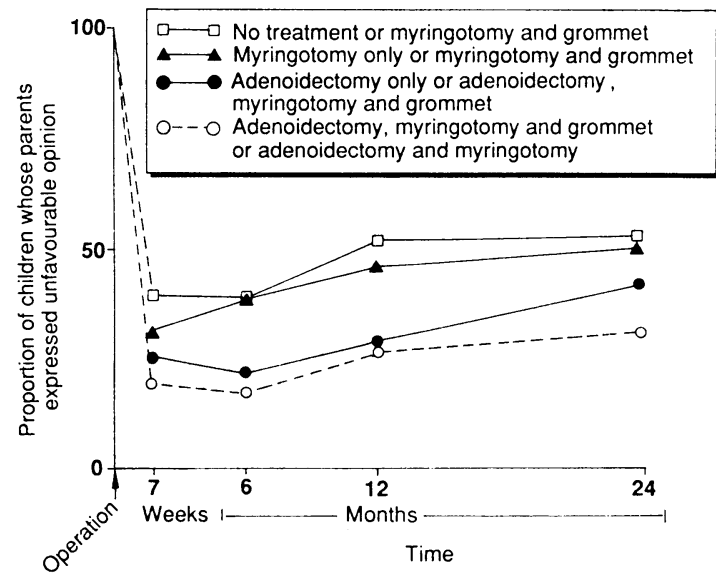

FIG 4-Proportion of children whose parents thought that their child's condition was unfavourable or uncertain at various times postoperatively according to treatment group 
(and occasionally the parents') dissatisfaction with a child's progress, which they believed warranted further surgical intervention. To cope with this problem the data were modified in the way we described. The results obtained with sensitivity analysis were robust to the various assumptions we made about those lost to follow up. Nevertheless, it is necessary to bear this adjustment in mind, particularly when considering data that related to the two year follow up.

It was clear that myringotomy plus grommet insertion produced a significant improvement in hearing which lasted for six to 12 months. Adenoidectomy resulted in only a modest improvement in hearing, though there was some evidence to suggest this was more long lasting than that obtained from the insertion of grommets. This view was supported by the finding that normal function of the middle ear (measured by impedance tympanometry) was restored in about half the children who underwent an adenoidectomy compared with only about $20 \%$ of children after myringotomy plus grommet insertion. If, however, the primary objective of surgery for glue ear is to restore hearing then this apparent advantage of adenoidectomy is irrelevant. To achieve a rapid and significant improvement in hearing myringotomy plus grommet insertion is the treatment of choice. The addition of an adenoidectomy produces little additional benefit. In this respect the results of this trial are consistent with those of several other studies. ${ }^{2-689}$ Considering the operative risks and the greater economic and social costs of adenoidectomy compared with myringotomy plus grommet insertion, our results offer little justification for continuing to use adenoidectomy in the routine treatment of glue ear. The finding that the proportion of parents who expressed satisfaction with the treatment that their child had received was higher among those whose children had had an adenoidectomy than in those whose children had not might be explained by the first group's knowledge that everything that might have been done had been done.

The need for clinicians to identify those children who would benefit from surgery is clear. Unfortunately, none of the 15 published randomised, controlled trials has considered the issue quantitatively. Our study has, however, investigated the sensitivity and specificity of preoperative findings in predicting the outcome of surgery. Despite the uncertainties surrounding the level of objectivity of audiometry this single measure appears to be a useful predictor of outcome. The use of preoperative hearing level both for ears that had grommets inserted and those that had not should have inhibited the effects of regression towards the mean.

Interpretation of the preoperative audiometry score as a predictor of outcome of surgery depends on the definition of a satisfactory outcome in terms of improvement in hearing and on attitudes to unnecessary operations on the one hand and to missed cases (children who might have benefited from surgery but who were not treated) on the other. The confidence intervals from this study were wide, but the implications for current practice are potentially dramatic. For example, if satisfactory outcome is defined as an improvement of $10 \mathrm{~dB}$ six months after surgery, and if a strategy of operating only on children with a hearing loss of $25 \mathrm{~dB}$ and above is adopted, then only 79 of the 127 children with complete data in this trial would have been operated on, of whom it might be expected that 30 would have benefited and 49 would not. Four children, however, who might have benefited would have been missed. Alternatively, setting the operation threshold at $20 \mathrm{~dB}$ would have resulted in 96 operations being performed, with 32 children expected to benefit, and two potential beneficiaries being missed. If the children in this trial were representative of children operated on for glue ear in England and Wales in 1986 then the adoption of a policy of only operating when the preoperative hearing loss is at least $25 \mathrm{~dB}$ would have had the following implications. Firstly, the total number of operations would have been reduced from 91000 to about 57000 , of which 21000 would have achieved a satisfactory improvement of $10 \mathrm{~dB}$ or more. Secondly, however, nearly 3000 of the 34000 children who would have been regarded as inappropriate for surgery under this policy would have been denied such an improvement.

These figures give only an indication of the scale of the problem. As in any trial, the sample used might not have been representative of the population of children undergoing surgery for glue ear and the effectiveness of the surgeons concerned might not have been typical. Also predictors that have been derived from one set of patients will generally not perform as well when used with another set, and greater precision is required. It will be necessary to test the predictors on other samples of children to confirm our results.

Finally, it is important to recognise that, as with most trials of surgery for glue ear, the effectiveness of the operations was assessed in terms of improvement in hearing. No attempt was made to determine any possible longer term effects-namely, improvements in language skills or in educational achievements.

We thank Rosemary Heddon for her help, members of the medical, nursing, and clerical staff of the department of otolaryngology, Radcliffe Infirmary, Oxford, Richard Gledhill and other audiometricians for taking on additional work, and Klim McPherson of the university department of community medicine and general practice for advice on design of the study. We are grateful for the financial support received from Oxfordshire Health Authority, Oxford Regional Health Authority, and the Department of Health and Social Security.

1 Black NA. Surgery for glue ear-a modern epidemic. Lancet 1984;i:835-7.

2 Maw AR, Herod F. Otoscopic, impedance, and audiometric findings in glue ear treated by adenoidectomy and tonsillectomy. A prospective randomise study. Lancet 1986; ;: 1399-402

3 Gates (iA, Avery CA, Prihoda TJ, et al. Effectiveness of adenoidectomy and tympanostomy tubes in the treatment of chronic otitis media with effusion. N Eingl f Med 1987;317:1444-51.

4 Roydhouse N. Adenoidectomy for otitis media with mucoid effusion. Ann Otol Rhinol Laryngol 1980;89(suppl 68):312-5.

5 Widemar L, Svensson C, Rynnel-Dagoo B, et al. The effect of adenoidectomy on secretory otitis media: a two year controlled prospective study. Clin Otolaryngol 1985;10:345-50.

6 Lildholdt T. Unilateral grommet insertion and adenoidectomy in bilatera secretory otitis media: preliminary report of the results in 91 children. secretory otitis media: prelimin
Clin Otolaryngol 1979;4:87-93.

7 Richards SH, Kilby D, Shaw JD, et al. Grommets and glue ears: a clinical trial. f Laryngol Otol 1971:85:17-22.

8 Bonding $\mathrm{P}$. Tos $M$, Poulsen $\mathrm{G}$. Unilateral insertion of grommets in bilateral secretory otitis media. Acta Otolaryngol 1982;Suppl 386:161-2.

9 To SS, Pahor AL, Robin PE. A prospective trial of unilateral grommets for bilateral secretory otitis media in children. Clin Otolaryngol 1984;9:115-7.

10 Fiellau-Nikolajsen M, Hojslet PE, Felding JU. Adenoidectomy for eustachia tube dysfunction: long term results from a randomised controlled trial. Acta Otolaryngol 1982; Suppl 386:129-31.

11 Rynnel-Dagoo B, Ahlborn A, Schiratzki H. Effects of adenoidectomy. A controlled two vear follow up. Ann Otol Rhinol Laryngol 1978;87:272-8.

12 Bulman $\mathrm{CH}$, Brook SJ, Berry MG. A prospective randomised trial of adenoidectomy versus grommet insertion in the treatment of glue ear Clin Otolaryngol 1984;9:67-75

13 Brown MJKM, Richards SH, Ambegaokar AG. Grommets and glue ear: a tive year follow up of a controlled trial. f $R$ Soc Med 1978;71:353-6.

14 Mandel EM, Bluestone CD, Paradise JL, et al. Efficacy of myringotomy with and without tympanostomy tube insertion in the treatment of chronic otitis media with effusion in infants and children: results for the first year of a randomised clinical trial. In: Lim DJ, Bluestone $\mathrm{CD}$, Klein JO, et al, eds. Recent advances in otitis media with effusion. Philadelphia: Decker, 1984:308-12.

15 Zielhuis GA, Rach GH, Van Den Broek P. Screening for otitis media with effusion in preschool children. Lancet 1989;i:311-4.

16 Archard JC. The place of myringotomy in the management of secretory otitis media in children. F Laryngol Otol 1967;81:309-15.

17 Black NA, Crowther J, Freeland A. The effectiveness of adenoidectomy in the treatment of glue ear: a randomised controlled trial. Clin Otolaryngol 1986;11:149-55.

18 Tos M. Poulsen G. Secretory otitis media. Late results of treatment with grommets. Archives of Otolarnngology 1976;102:672-5

19 Paradise JL, Smith CG, Bluestone CD. Tympanometric detection of middle ear effusion in infants and young children. Pediatrics 1976:58:198-210.

20 Black NA. The aetiology of glue ear - a case control study. Int f of Pediat Otorhinolarvngol 1985;9:121-33.

(Accepted 30 March 1990) 